\title{
THE IMPACT OF LOW TEMPERATURE ON SEED GERMINATION OF TWO DESERT SPECIES IN JUNGGAR BASIN OF CHINA
}

\author{
PENG, M. W. - WANG, M.*-JiAng, P. - ChANG, Y. L. - CHU, G. M.* \\ Department of Forestry, Agricultural College, Shihezi University \\ Road of North 4th, Shihezi City, Xinjiang 832003, China \\ *Corresponding authors \\ e-mail:wangm1205@163.com,chgmxj@163.com \\ (Received $8^{\text {th }}$ Oct 2017; accepted $27^{\text {th }}$ Feb 2018)
}

\begin{abstract}
Germination behaviour plays an important role for seedling regeneration and the sustainable development of population in arid and semiarid areas. The objectives of the study were to explore germination characteristics of Anabasis aphylla and Haloxylon ammodendron under low temperature conditions and their ecological significance in Junggar basin of China. We combined the Logistic function and the thermal time equation, and used non-linear regression to estimate the base temperature and the thermal time for germination of both species. Germination experiments were carried out in the illumination incubators with 6 temperature gradients $\left(20 / 15{ }^{\circ} \mathrm{C}, 15 / 10{ }^{\circ} \mathrm{C}, 10 / 5{ }^{\circ} \mathrm{C}, 5 / 2{ }^{\circ} \mathrm{C}, 2{ }^{\circ} \mathrm{C}\right.$ and $2 /-$ $3{ }^{\circ} \mathrm{C}$ ) for 15 days. Final germination percentages of the two species were not obviously different and were higher than $90 \%$ in different temperature treatments, and low temperature only inhibited germination speed. Moreover, germination percentages of the two species surpassed $50 \%$ in the eighth day under low temperature conditions. The base temperature and thermal time of $A$. aphylla was $0.54{ }^{\circ} \mathrm{C}$ and $9.89^{\circ} \mathrm{C}$, while $H$. ammodendron was $0.79^{\circ} \mathrm{C}$ and $7.26^{\circ} \mathrm{C}$, respectively. The results showed that the two desert species adapted to the low temperature habitat and took advantage of humid soil conditions to grow in the snow-melting period.
\end{abstract}

Keywords: seed germination, desert plant, snow-melting, base temperature, thermal time model, harsh habitats

\section{Introduction}

Germination is a crucial stage in the life cycle of plants, however, this stage is highly unpredictable over space and time (Tlig et al., 2008). In germination experiments, temperature is an important and determining factor regarding the time of germination (Khan and Ungar, 1998). In general, it is thought that germination starts above $10{ }^{\circ} \mathrm{C}$ (Huang et al., 2003; Tobe et al., 2000). However, several researchers suggested that some species could germinate under low temperature conditions (Sun, 2015; Han et al., 2011; Körner, 2003; Shimono and Kudo, 2005; Zhang, 2010). For example, Shimono and Kudo (2005) actually observed that seedlings of Peucedanum multivittatum had already emerged at the time of snow-melting in the snow-bed habitat. However, limited information is available for seed germination at low temperature (Huang et al., 2003). So, it is significative for desert seeds to germinate during snowmelt period.

As a result of long-term adaptation to the environment, the majority of plant seeds have a specific requirement of base temperature $\left(T_{\mathrm{b}}\right)$ and thermal temperature value for triggering germination (Steadman et al., 2004). When the ambient temperature reaches the base germination temperature, seeds can become receptive to the thermal temperature, once the thermal temperature reaches the specific value for a given species, the seeds can germinate (Steinmaus et al., 2000). Depending on the accumulation process of environmental temperature during seed germination, the thermal time model 
can quantify the influence of external environment on seed germination in a certain degree (Liu et al., 2011). The process of seed germination is related to the accumulation of environment temperature, only the thermal time accumulated to a certain extent can promote seed germination, thermal time is generally considered to be accumulated when the environment temperature exceeds the base temperature of seed germination, and for seeds of the same species the base temperature is constant (Dahal et al., 1990). Thermal time models were derived for germination and shoot emergence using a range of sub-optimal and optimal temperatures $\left(\leq 20^{\circ} \mathrm{C}\right)$ for each provenance, this temperature range was selected as these models assume that there are linear relationships between rate and temperature (Finch-Savage and Whalley, 2006).

Haloxylon ammodendron and Anabasis aphylla are two shrubs of Chenopodiaceae, mainly distributed in northwest of China. H. ammodendron has many characteristics of adapting to drought, salinity, poor nutrition, strong wind, sand movement, and high light intensity (Huang et al., 2003). As an important component of old Mediterranean flora, it widely spread in Junggar basin, northeast of the Tarim basin and other desert areas on a range of soils and is a representative psammophytic species (Wang et al., 2014). $H$. ammodendron is a precious biological resource in the arid desert region. Besides its ecological value, $H$. ammodendron also has great economic value. A. aphylla population mainly distributes in diluvial fan, lowland among dunes, Gobi and hillside, and presents staggered distribution with $H$. ammodendron population in the desert-oasis ecotone (Wang et al., 2015). Several investigations have been conducted on germination and community traits of $H$. ammodendron and A. aphylla (Huang et al., 2003; Wang et al., 2014, 2015; Chu et al., 2014a, b). A. aphylla plays an important role in saline-alkali land, rehabilitated fissure and windbreak and sand fixation in the desert area, and has a certain significance for maintaining the water and soil safety of the alluvial fan in the foreland. It has a good application for the follow-up industrial development of returning farmland to forestry prospect. In Junggar basin, the habitats are harsh, coupled with improper human exploitation, so the habitats are further destroyed, and the seedlings of various plants are naturally difficult to be regenerated. H. ammodendron and A. aphylla are the dominant species in this area and can survive in this harsh environment. Studies have shown that temperature of Junggar basin increased in early April, resulting in the rapid drying of the shallow layer of soil, which is not conducive to the growth of $H$. ammodendron seedlings (Huang et al., 2008). In the field, our observations show that a large number of $H$. ammodendron and $A$. aphylla seedlings germinate during the snowmelting period in March. Therefore, studying the adaptability of desert plants at low temperatures is of great significance to ecological construction.

The objective of this study was to explore the characteristics and ecological adaptation of seed germination under low temperature conditions. It is necessary to understand seed germination in adaption to harsh environment, and also to study the evolution of plant life history.

\section{Materials and methods}

\section{Experimental materials and habitat conditions}

Fresh and matured seeds of $H$. ammodendron and A. aphylla were collected in the desert on the southern edge of the Junggar basin in Xinjiang $\left(45^{\circ} 22^{\prime} 43.4^{\prime \prime} \mathrm{N}\right.$, $84^{\circ} 50^{\prime} 32.5^{\prime \prime} \mathrm{E}$; altitude is $843 \mathrm{~m}$ ). The annual mean temperature varies from 5 to $9^{\circ} \mathrm{C}$, and minimum winter temperature varies from -30 to $-41^{\circ} \mathrm{C}$ and maximum summer 
temperatures are $30-40{ }^{\circ} \mathrm{C}$. Snow-melting appears at the end of winter, together with the rainfall that occurs in summer and annual precipitation amounts from $100 \mathrm{~mm}$ to $250 \mathrm{~mm}$. Annual potential evaporation is greater than $2000 \mathrm{~mm}$ (Wang et al., 2014). In Junggar basin, the snow-melting period is about 10 days in March, the average daytime temperature is higher than $0{ }^{\circ} \mathrm{C}$ and the maximum temperature is basically maintained at $7-14{ }^{\circ} \mathrm{C}$, while the minimum temperature is below $0{ }^{\circ} \mathrm{C}$. So, during the snow-melting period, the surface of the soil is repeatedly frozen and thawed (Fig. 1).
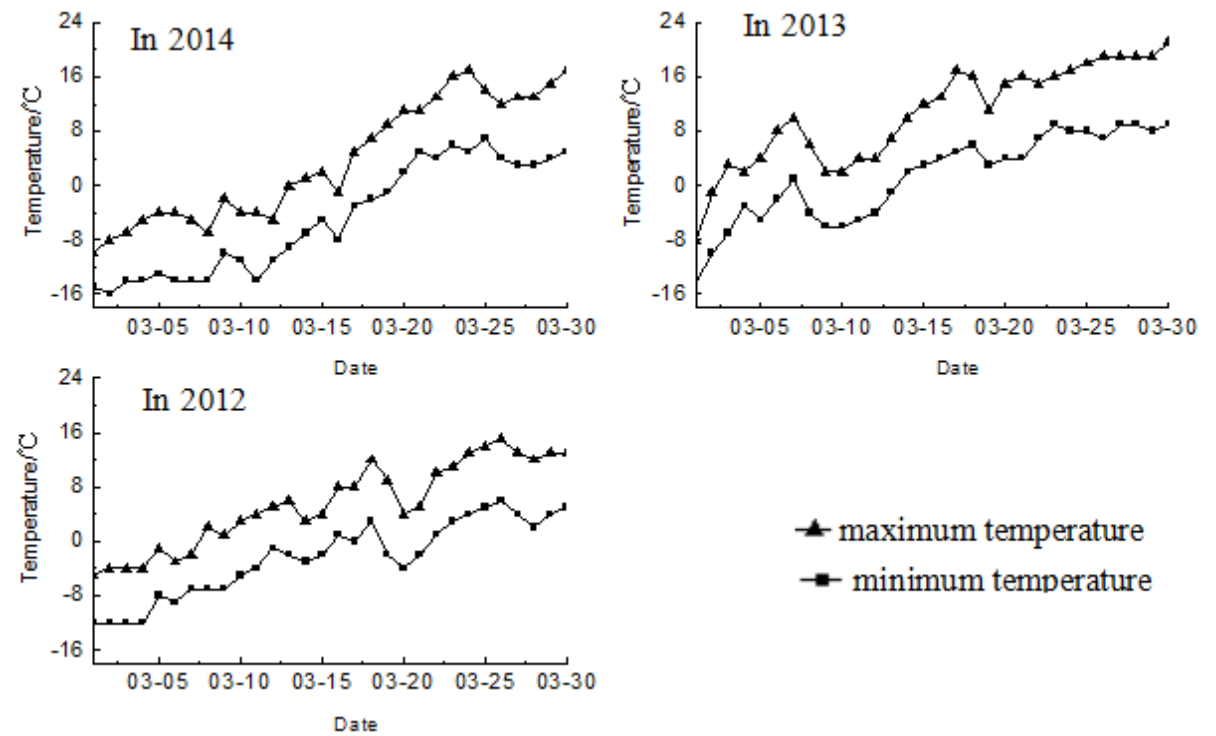

Date

Figure 1. Temperature conditions of the snow-melting period in the study area

The seeds of both species are similar in shape and have perianth segments. The seed of $H$. ammodendron is larger than A. aphylla, and both seed is gray or black (Fig. 2). Its average diameter is $2.13 \mathrm{~mm}$ and $1.88 \mathrm{~mm}$, while thousand seed weight is $1.90 \mathrm{~g}$ and $1.45 \mathrm{~g}$, respectively. It was found through preliminary experiments that seeds of both species could germinate at $2{ }^{\circ} \mathrm{C}$ (Fig. 3).

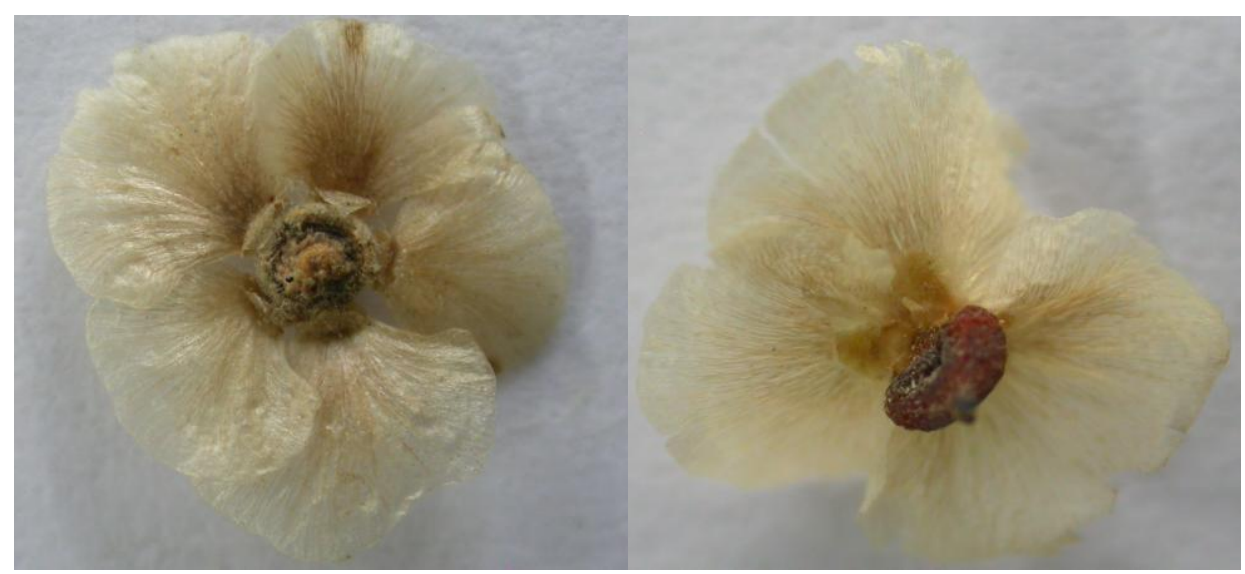

Figure 2. The pictures of two desert plant seeds morphology (H. ammodendron seed on the left and $A$. aphylla on the right) 


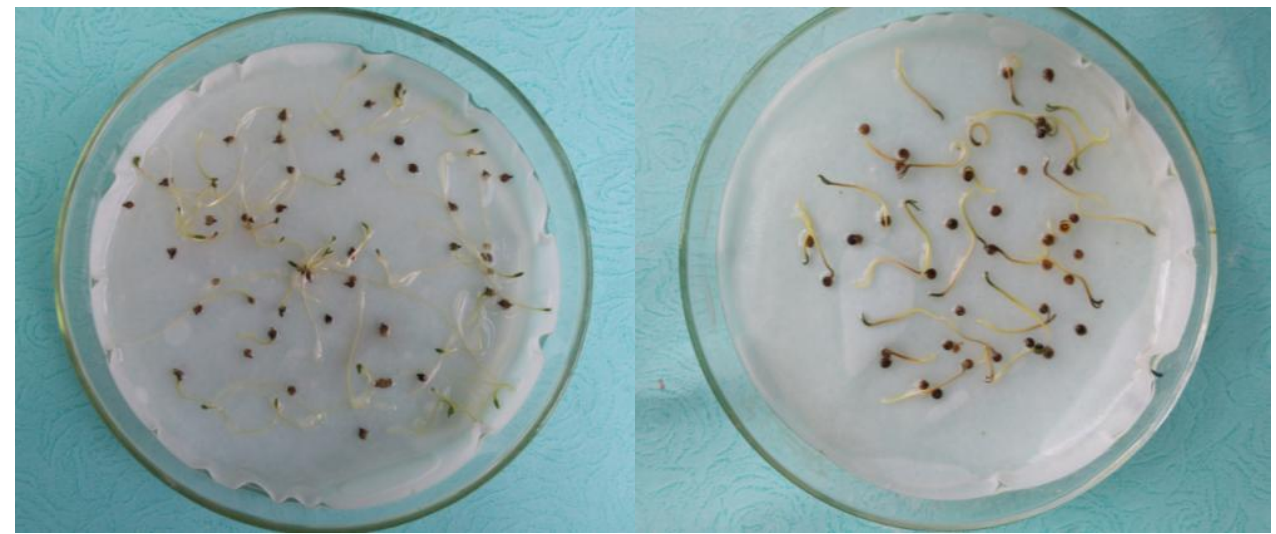

Figure 3. The pictures of two desert plant seeds germinated at $2{ }^{\circ} \mathrm{C}(\mathrm{H}$. ammodendron seed on the left and A. aphylla on the right)

\section{Experimental methods}

\section{Experimental design of germination under different temperatures}

Germination experiments were carried out in Petri dishes ( $9 \mathrm{~cm}$ in diameter) on two layers of filter paper (GB/T1914-93, Hangzhou Xinhua Paper Ltd., China) moistened with $10 \mathrm{ml}$ of distilled solution. The variable temperatures of day and night were in control of $20 / 15{ }^{\circ} \mathrm{C}, 15 / 10{ }^{\circ} \mathrm{C}, 10 / 5{ }^{\circ} \mathrm{C}, 5 / 2{ }^{\circ} \mathrm{C}, 2{ }^{\circ} \mathrm{C}$ and $2 /-3{ }^{\circ} \mathrm{C}$ individually. All Petri dishes were kept in an illumination incubator with $12 \mathrm{~h}$ photoperiod (LRH-250-G Illuminating Incubator, Guangdong Medicine Apparatus Manufactory, Guangdong, China) and freeze temperature were conducted in Ronshen Refrigerator (BCD$232 \mathrm{YMB} / \mathrm{X} 1$ ). For all treatments (6 temperature gradients), four replicates of 40 seeds each were used in the experiment. Germinated seeds were recorded daily for 15 days. Seed was considered to have germinated with the emergence of the radicle (Chu et al., 2014b).

\section{Experimental design of thermal temperature model}

Based on the thermal time model standard, 5 constant temperature gradients were set up experimentally. For all treatments, four replicates of 40 seeds each were used for testing. Germination trials were carried out in Petri dishes with two layers of filter paper, the number of seed germination was recorded every $12 \mathrm{~h}$. In the process of seed germination, the thermal time $\left(\theta_{T(g)}\right)$ needed for the germination percentage of $\mathrm{g}$ is calculated by the following formula (Eq. 1):

$$
\theta_{T(g)}=\left(T-T_{b}\right) t_{g}
$$

$T$ is temperature of the experiment, $T_{b}$ is the base temperature of seed germination, $T_{g}$ is the number of days required to accumulate the germination percentage of $\mathrm{g}$.

By using the Logistic function (Eq. 2) curve fitting, the relevant parameters $m, k, b$ and the base temperature $\left(T_{\mathrm{b}}\right)$ of seed germination can be obtained.

$$
g=\frac{m}{1+e^{-k\left(T-T_{b}\right) t+b}}
$$


By using the thermal time to achieve the germination percentage of $g$ to estimate the thermal time value of seed germination, $\theta_{T(50 \%)}$ was calculated by Equation 3 and fitting results $m, k, b$ and $g=50 \%$.

$$
\theta_{T(g)}=\frac{1}{k}\left(b+\ln \frac{g}{m-g}\right)
$$

\section{Data analysis}

Excel 2016 was used to analyze the experimental data. SPSS 19.0 software was used to make significant variance analysis of germination index, and non-linear fitting Logistic function to get the parameters of thermal temperature, and utilize Origin 8.5 to draw the graph.

\section{Results}

\section{Seed germination characteristics of two desert species}

As a whole, with the decrease of temperature, germination speed of H. ammodendron and $A$. aphylla seed increased slowly. Germination periods of high temperatures $\left(20 / 15^{\circ} \mathrm{C}\right.$ and $\left.15 / 10^{\circ} \mathrm{C}\right)$ were less than 7 days while low temperatures $\left(5 / 2{ }^{\circ} \mathrm{C}, 2{ }^{\circ} \mathrm{C}\right.$ and $2 /-3^{\circ} \mathrm{C}$ ) were more than 11 days. The experiment ended on the 15 th day, the germination percentage of both species tended to be stable at a certain level, and the low temperatures slowed down the seed germination speed (Fig. 4). The initial germination time of $H$. ammodendron and $A$. aphylla increased with the decrease of temperature, and the germination index decreased gradually, but the final germination percentage was over $90 \%$ with no significant difference (Table 1).
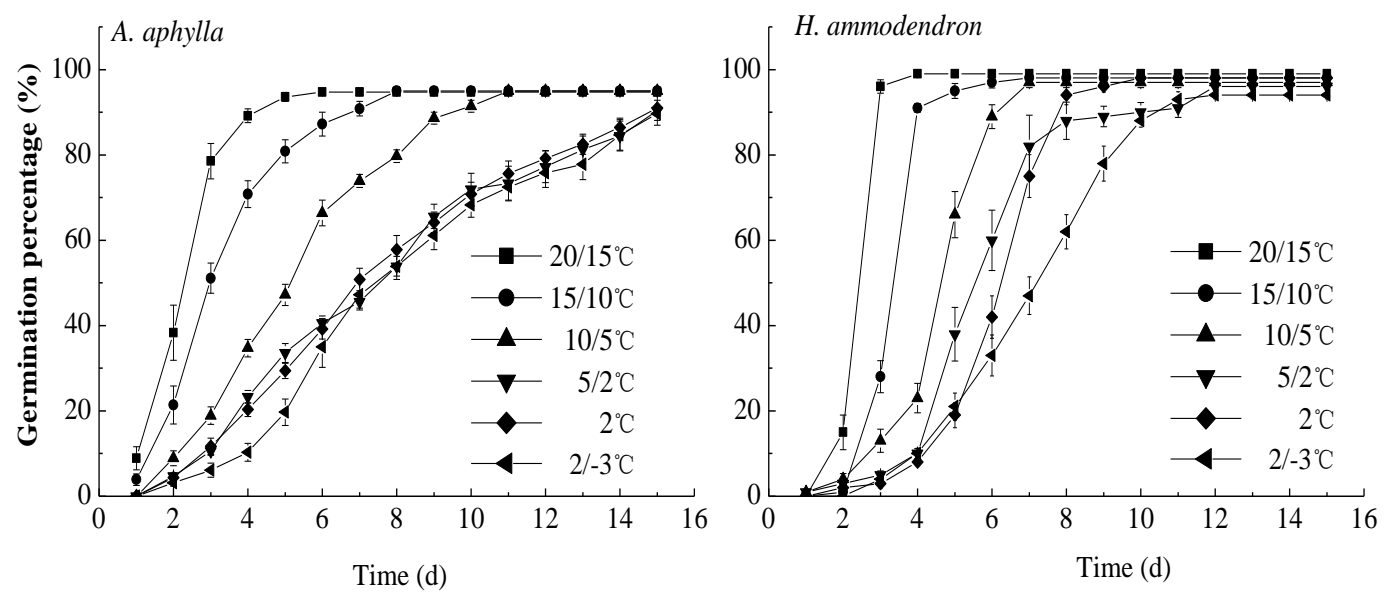

Figure 4. Seed germination percentages of A. aphylla and H. ammodendron

\section{Thermal temperature model analysis of two desert species germination}

The parameter estimates $m, k, b, T_{b}$ ( \pm standard error) obtained by fitting the Logistic equation (Eq. 2) are shown in Table 2. According to the above formula (Eq. 3), the relationship between cumulative germination percentage and thermal temperature of $H$. ammodendron was obtained, which is $\theta_{\tau(s)}=\frac{1}{0.90}\left(6.18+\ln \frac{g}{0.85-g}\right)$. A. aphylla is 
$\theta_{T(g)}=\frac{1}{0.37}\left(3.36+\ln \frac{g}{0.87-g}\right)$. When the cumulative germination percentage $\mathrm{g}=0.5$, the thermal temperature of $\mathrm{H}$. ammodendron is $7.26^{\circ} \mathrm{C}$, A. aphylla is $9.89^{\circ} \mathrm{C}$. The base temperature of both species is low, both at about $0{ }^{\circ} \mathrm{C}$. The determination coefficient $\mathrm{R}^{2}$ is 0.94 (Table 2).

Table 1. Seed germination characteristics of A. aphylla and H. ammodendron $(p<0.05)$

\begin{tabular}{c|c|c|c|c|c|c}
\hline \multirow{2}{*}{$\begin{array}{c}\text { Treatment } \\
\left({ }^{\circ} \mathrm{C}\right)\end{array}$} & \multicolumn{2}{|c|}{$\begin{array}{c}\text { Final germination } \\
\text { percentage (\%) }\end{array}$} & \multicolumn{2}{|c|}{$\begin{array}{c}\text { Initiate germination time } \\
(\mathbf{h})\end{array}$} & \multicolumn{2}{c}{ Germination index } \\
\cline { 2 - 6 } & Species1 & Species2 & Species1 & Species2 & Species1 & Species2 \\
\hline $20 / 15^{\circ} \mathrm{C}$ & $95 \pm 2 \mathrm{a}$ & $99 \pm 2 \mathrm{a}$ & $2 \pm 1 \mathrm{~b}$ & $12 \pm 1 \mathrm{~b}$ & $16 \pm 3 \mathrm{a}$ & $14 \pm 1 \mathrm{a}$ \\
$15 / 10^{\circ} \mathrm{C}$ & $95 \pm 3 \mathrm{a}$ & $98 \pm 2 \mathrm{a}$ & $4 \pm 3 \mathrm{~b}$ & $12 \pm 1 \mathrm{~b}$ & $13 \pm 2 \mathrm{~b}$ & $11 \pm 1 \mathrm{~b}$ \\
$10 / 5^{\circ} \mathrm{C}$ & $95 \pm 2 \mathrm{a}$ & $97 \pm 3 \mathrm{a}$ & $26 \pm 7 \mathrm{a}$ & $24 \pm 12 \mathrm{ab}$ & $8 \pm 1 \mathrm{c}$ & $9 \pm 1 \mathrm{c}$ \\
$5 / 2{ }^{\circ} \mathrm{C}$ & $90 \pm 8 \mathrm{a}$ & $96 \pm 6 \mathrm{a}$ & $26 \pm 6 \mathrm{a}$ & $37 \pm 22 \mathrm{a}$ & $6 \pm 1 \mathrm{~d}$ & $7 \pm 2 \mathrm{~d}$ \\
$2{ }^{\circ} \mathrm{C}$ & $91 \pm 5 \mathrm{a}$ & $98 \pm 3 \mathrm{a}$ & $32 \pm 14 \mathrm{a}$ & $45 \pm 17 \mathrm{a}$ & $6 \pm 1 \mathrm{~d}$ & $6 \pm 1 \mathrm{de}$ \\
$2 /-3{ }^{\circ} \mathrm{C}$ & $90 \pm 7 \mathrm{a}$ & $95 \pm 2 \mathrm{a}$ & $38 \pm 22 \mathrm{a}$ & $48 \pm 6 \mathrm{a}$ & $5 \pm 1 \mathrm{~d}$ & $6 \pm 1 \mathrm{e}$ \\
\hline
\end{tabular}

Means within a column at each treatment with the same letter are not significantly different. Species 1 is A. aphylla and Species2 is H. ammodendron

Table 2. Non-linear regression analysis results and the average value of thermal time $\theta_{T}(50 \%)$

\begin{tabular}{c|c|c|c|c|c|c}
\hline Species & $\boldsymbol{m} \pm \mathbf{S E}$ & $\boldsymbol{k} \pm \mathbf{S E}$ & $\boldsymbol{b} \pm \mathbf{S E}$ & $\boldsymbol{T}_{\mathbf{b}} \pm \mathbf{S E}\left({ }^{\circ} \mathbf{C}\right)$ & $\boldsymbol{\theta}_{\mathbf{T}(\mathbf{5 0} \%)}\left({ }^{\circ} \mathbf{C} \mathbf{d}\right)$ & $\mathbf{R}^{\mathbf{2}}$ \\
\hline H. ammodendron & $0.85 \pm 0.012$ & $0.90 \pm 0.117$ & $6.18 \pm 0.775$ & $0.79 \pm 0.065$ & 7.26 & 0.94 \\
A. aphylla & $0.87 \pm 0.013$ & $0.37 \pm 0.040$ & $3.36 \pm 0.340$ & $0.54 \pm 0.114$ & 9.89 & 0.94 \\
\hline
\end{tabular}

$m, k, b$ and $T_{\mathrm{b}}$ are the values of parameter estimates. $m$ : the approximate final germination percentage; $k$ : the rate of increase in germination percentage; $b$ : the value related to the lag in germination; $T_{\mathrm{b}}$ : the base or minimum temperature for germination; $\theta_{\mathrm{T}(50 \%)}$ : the median thermal temperature. $\mathrm{R}^{2}$ and $\mathrm{SE}$ are the coefficient of determination and standard error of parameter respectively

\section{Discussion}

The research indicates that the majority of seeds germinated optimally in the temperature range of $10-20^{\circ} \mathrm{C}$, in this temperature range, seeds have a high germination percentage, short initial germination time and high germination index (Table 1). But soil humidity was not suitable for seed germination of both species when soil surface temperature surpassed $10{ }^{\circ} \mathrm{C}$ in the field (Huang et al., 2008). In Junggar basin, the most of desert species can utilize snow-melting water that is available to better germination and seedling survival before the desiccation of early spring (Huang et al., 2009). In the short snow-melting period (12-15 days), air temperature usually is under $15^{\circ} \mathrm{C}$ and the soil surface temperature is less than $5{ }^{\circ} \mathrm{C}$ (Sun, 2015). Therefore, germination under the low temperature condition has important ecological implications in plant adaptation to drought stress in arid and semi-arid zones. Meanwhile, both species have a lot of seeds germinated in snow-melting period.

In Junggar basin, the research of Han et al. (2011) showed that the snow melted in early spring, during which the maximum air temperature was maintained at $0-15^{\circ} \mathrm{C}$ and the relative humidity was 50-60\%, and the seeds of Anabasis elatio germinated on the 
mother plants and developed into viviparous seedling. Similarly, Suaeda physophora can germinate at $10{ }^{\circ} \mathrm{C}$ and even at $0{ }^{\circ} \mathrm{C}$ from field observation ( $\mathrm{Li}$ and Zhang, 2007). The phenomenon was consistent with the results from Huang et al. (2003). The results of Zhang et al. (2010) showed germination percentage of $H$. ammodendron and Haloxylon persicum was over $80 \%$ under $2{ }^{\circ} \mathrm{C}$. In addition, Sun (2015) suggested desert seeds started to germinate only two days when snow melted at the average daily temperature (day/night) of $3.5^{\circ} \mathrm{C}\left(6.7 /-0.5^{\circ} \mathrm{C}\right)$ and a soil volumetric water content of $24.2 \%$. Therefore, seed germination under low temperatures was a common behaviour for desert plants.

Junggar basin is one of the driest regions of the Eurasian continent. The annual evaporation is 10 times greater than the annual precipitation in the region (Song et al., 2006). The soil may dry up quickly after short periods of rainfall or snowmelt, resulting in a substantial rise in the mortality rate of desert plant seedlings (Huang et al., 2009). So, early germination is of significant importance. Low temperatures only slowed down germination speed in the snow-melting period, and weak salt and high humidity conditions were favourable to desert plant germination in early spring (Chu et al., 2014). Compared with the time of seed germination of different species, seed of early germination was found to provide the advantage for seedling emergency. The seedlings with a longer growth period were as better competitors, gained more nutrition and had a higher precompetitive survival than those with shorter growth period (Körner, 2003; Shimono and Kudo, 2005; Huang et al., 2008; Gornish et al., 2015).

The base temperature of seed germination may be an adaptive feature of plants, and species germinated under low temperatures have a relatively low base temperature $\left(T_{b}\right)$ (Steinmaus et al., 2000). In previous studies, the $\mathrm{T}_{\mathrm{b}}$ of temperate species is between 0$4{ }^{\circ} \mathrm{C}$ (Angus et al., 1980; Hur and Nelson, 1984; Moot et al., 2000). In this study, A. aphylla and $H$. ammodendron are temperate species, and their base temperature was $0.54{ }^{\circ} \mathrm{C}$ and $0.79^{\circ} \mathrm{C}$, respectively. This is consistent with previous studies. In the same temperature conditions, species with low base temperature can quickly germinate (Ross and Harper, 1972). Trudgill (2005) showed that germination adapted to low temperature environment requires higher thermal temperature and lower $\mathrm{T}_{\mathrm{b}}$ than those adapted to warm environment. Liu et al. (2011) studied the base temperature and thermal temperatures of 12 Compositae species in the Qinghai-Tibet plateau, the base temperatures of the 12 Compositae species ranged from -1.4 to $1.5^{\circ} \mathrm{C}$ with an average around $0{ }^{\circ} \mathrm{C}$, and the average thermal temperature was $94.5^{\circ} \mathrm{C}$. Similarly, Larsen (2005) showed that the base temperature for Danish Festuca rubra was $2.7^{\circ} \mathrm{C}$ and the thermal temperature was $60^{\circ} \mathrm{C}$. In this study, the base temperature of both species was about $0{ }^{\circ} \mathrm{C}$, thermal temperature was $9.89^{\circ} \mathrm{C}$ and $7.26^{\circ} \mathrm{C}$, respectively, compared with the previous results. The thermal temperature of the two species was lower than the thermal temperature of other species when the base temperature was similar, indicating that the species in this study not only could germinate at a low temperature, but also thermal temperature was low. In the early spring short snow-melting conditions, plant seeds will quickly germinate and occupy the habitat, with the time and space advantages, this is the result of long-term adaptation to environmental conditions. Therefore, with a consistent water supply in early spring, the seed can tolerate low temperatures to germinate, because of the available water from the melting snow, more heat and nutrients accumulated that are essential for the survival of the seedlings at later stages. 


\section{Conclusions}

The final germination percentage of both species had no significant difference in 6 temperature gradients, and low temperature only slowed down germination speed. The base temperature and thermal temperature of both species were low. Therefore, seed germination of $H$. ammodendron and A. aphylla requires less energy, and this is conducive to early germinate for desert seed. The two species have opportunistic strategies for germination, and they can germinate quickly with short-term low temperature and snow water conditions.

\section{Prospect}

Seed germination is a crucial stage of plant life cycle, which directly determines establishment and regeneration of plant population. In arid and semi-arid areas desert species have formed some peculiar strategies of germination adapted to the harsh habitat. We found that desert species represented by $H$. ammodendron and A. aphylla have the characteristic of germination during snowmelt period. At present, there have been a lot of research studies on the physiological and ecological aspects of both species at low temperatures. However, few research studies have been done on the molecular level. Therefore, we are also carrying out molecular study. This study is expected not only to explore the anti-freezing pathway and mechanisms of the two species, but also to find some new anti-freezing substances, which will provide some ideas for gene engineering research of anti-freezing for desert plants.

Acknowledgements. The research was supported by the Program of the National Natural Science Foundation of China (31570595, 31660194), General Financial Grant of the China Postdoctoral Science Foundation (2017M613253) and Scientific Research Foundation of Shihezi University for Advanced Talents (RCZX201518, RCZX201521).

\section{REFERENCES}

[1] Angus, J. F., Cunningham, R. B., Moncur, M. W. (1980): Phasic development in field crops I. Thermal response in the seedling phase. - Field Crops Research 3: 365-378.

[2] Chu, G. M., Wang, M., Zhang, S. X. (2014a): Spatial patterns and associations of dominant woody species in desert-oasis ecotone of South Junggar Basin, NW China. Journal of Plant Interactions 9(1): 738-744.

[3] Chu, G. M., Wang, M., Zhang, S. X. (2014b): Factors influencing seed germination of medicinal plant Anabasis aphylla L. in salt desert of Xinjiang. China. - Vegetos 27(1): 123-129.

[4] Dahal, P., Bradford, K. J. (1990): Effects of priming and endosperm integrity on seed germination rates of tomato genotypes. II. Germination at reduced water potential. Journal of Experimental Botany 41: 1441-1453.

[5] Finch-Savage, W., Whalley, R. (2006): Germination-Field Energence Models. - In: Black, M., Bewley, J. D., Halmer, P. (eds.) The Encyclopedia of Seeds: Science Technology and Uses. Cromwell Press, Trowbridge.

[6] Gornish, E. S., Aanderud, Z. T., Sheley, R. L. (2015): Altered snowfall and soil disturbance influence the early life stage transitions and recruitment of a native and invasive grass in a cold desert. - Oecologia 177(2): 595-606.

[7] Han, J. X., Wei, Y., Yan, C., An, S. Z. (2011): The vivipary characteristic of Anabasis elatior and its ecological adaptation. - Chinese Acta Ecologica Sinica 31(10): 2662-2668. 
[8] Huang, Z. Y., Zhang, X. S., Zheng, G. H., Gutterman, Y. (2003): Influence of light, temperature, salinity and storage on seed germination of Haloxylon ammodendron. Journal of Arid Environments 55: 453-464.

[9] Huang, P. Y., Xiang, B., Li, Q. J., Xu, Z. H. (2009): Relationship between Haloxylon ammodendron seedling dynamics and habitat before summer. - Chinese Journal of Desert Research 29(1): 87-94.

[10] Huang, P. Y., Li, Q. J., Yuan, S. F. (2008): Effects of climate change on Haloxylona mmodendron community in southern edge of Zhunger basin. - Chinese Acta Ecologica Sinica. 28(12): 6051-6059.

[11] Hur, S. N., Nelson, C. J. (1984): Temperature effects on germination of Birdsfoot Trefoil and Seombadi. - Bulletin of the Agricultural College, Chonbuk National University (Korean Republic) 77(4): 557-560.

[12] Khan, M. A., Ungar, I. A. (1998): Germination of the salt tolerant shrub Suaeda fruticosa from Pakistan: salinity and temperature responses. - Seed Science and Technology 26: 657-667.

[13] Körner, C. (2003): Alpine Plant Life: Functional Plant Ecology of High Mountain Ecosystems. - Springer-Verlag, Berlin, Heidelberg.

[14] Li, L., Zhang, X. M. (2007): Germination strategies of two halophytes in salt desert of northwestern China. - Science in China Series D-earth Sciences 50: 115-121.

[15] Liu, W., Liu, K., Zhang, C. (2011): Effect of accumulated temperature on seed germination - a case study of 12 Compositae species on the eastern Qinghai-Tibet Plateau of China. - Chinese Journal of Plant Ecology 35(7): 751-758.

[16] Larsen, S. U., Bibby, M. B. (2005): Differences in thermal time requirement for germination of three turfgrass species. - Crop Science 45: 2030-2037.

[17] Moot, D. J., Scott, W. R., Roy, A. M., (2000): Base temperature and thermal time requirements for germination and emergence of temperate pasture species. - New Zealand Journal of Agricultural Research 43(1): 15-25.

[18] Ross, M. A., Harper, J. L. (1972): Occupation of biological space during seedling establishment. - Journal of Ecology 60(1): 77-88.

[19] Scott, S. J., Jones, R. A., Williams, W. A. (1984): Review of data analysis methods for seed germination. Crop Science 24: 1192-1199.

[20] Shimono, Y., Kudo, G. (2005): Comparisons of germination traits of alpine plants between fellfield and snowbed habitats. - Ecological Research 20: 189-197.

[21] Song, J., Feng, G., Zhang, F. S. (2006): Salinity and temperature effects on germination for three salt-resistant halophytes, Halostachys caspica, Kalidium foliatum and Halocnemum strobilaceum. - Plant and Soil 279: 201-207.

[22] Steadman, K. J., Pritchard, H. W. (2004): Germination of Aesculus hippocastanum, seeds following cold-induced dormancy loss can be described in relation to a temperaturedependent reduction in base temperature $\left(\mathrm{T}_{\mathrm{b}}\right)$ and thermal time. - New Phytologist 161(2): 415-425.

[23] Steinmaus, S. J., Prather, T. S., Holt, J. S. (2000): Estimation of base temperatures for nine weed species. - Journal of Experimental Botany 51(343): 275.

[24] Sun, Y. Y. (2012): Drought adaptation characteristics of plant seedling establishment in Junggar Desert. - Shihezi University, Shihezi (in Chinese).

[25] Tlig, T., Gorai, M., Neffati, M. (2008): Germination responses of Diplotaxis harra to temperature and salinity. - Flora 203: 421-428.

[26] Tobe, K., Li, X. M., Omasa, K. (2000): Effects of sodium chloride on seed germination and growth of two Chinese desert shrubs, Haloxylon ammodendron and Haloxylon persicum. - Australian Journal of Botany 48: 455-460.

[27] Trudgill, D. L., Honek, A., Li. D. (2015): Thermal time--concepts and utility. - Annals of Applied Biology 146(1): 1-14. 
[28] Wang, M., Zhang, S. X., Chu, G. M. (2014): Point pattern analysis of different life stages of Haloxylon ammodendron in Desert-oasis ecotone of south Junggar basin. - Polish Journal of Environmental Studies 23(6): 367-373.

[29] Wang, M., Li, Y. Y., Niu, P. X., Chu, G. M. (2015): Spatial pattern formation and intraspecific competition of Aanbasis aphylla L. population in the diluvial fan of Junggar basin, NW China. - Pakistan Journal Botany 47(2): 543-550.

[30] Zhang, S. J. (2010): Study on natural cure of main plant species at initialized process in the south marginal zone of the Junggar Basin. - Chinese Arid Environmental Monitoring 24: 89-93. 